\title{
The Relationship between Blood Flow and Neuronal Activity in the Rodent Olfactory Bulb
}

\author{
Emmanuelle Chaigneau, ${ }^{1,2}$ Pascale Tiret, ${ }^{1,2 *}$ Jérôme Lecoq, $^{1,2 *}$ Mathieu Ducros, ${ }^{1,2}$ Thomas Knöpfel, ${ }^{3}$ and Serge Charpak ${ }^{1,2}$ \\ ${ }^{1}$ Institut National de la Santé et de la Recherche Médicale U603, 75006 Paris, France, ${ }^{2}$ Laboratory of Neurophysiology, Université Paris Descartes, 75006 \\ Paris, France, and ${ }^{3}$ Laboratory for Neural Circuit Dynamics, Riken Brain Science Institute, 2-1 Hirosawa, Wako-shi, Saitama 351-0198, Japan
}

In the brain, neuronal activation triggers an increase in cerebral blood flow (CBF). Here, we use two animal models and several techniques (two-photon imaging of CBF and neuronal calcium dynamics, intracellular and extracellular recordings, local pharmacology) to analyze the relationship between neuronal activity and local CBF during odor stimulation in the rodent olfactory bulb. Application of glutamate receptor antagonists or tetrodotoxin directly into single rat olfactory glomeruli blocked postsynaptic responses but did not affect the local odor-evoked CBF increases. This suggests that in our experimental conditions, odor always activates more than one glomerulus and that silencing one of a few clustered glomeruli does not affect the vascular response. To block synaptic transmission more widely, we then superfused glutamate antagonists over the surface of the olfactory bulb in transgenic G-CaMP2 mice. This was for two reasons: (1) mice have a thin olfactory nerve layer compared to rats and this will favor drug access to the glomerular layer, and (2) transgenic G-CaMP2 mice express the fluorescent calcium sensor protein G-CaMP2 in mitral cells. In G-CaMP2 mice, odor-evoked, odor-specific, and concentration-dependent calcium increases in glomeruli. Superfusion of glutamate receptor antagonists blocked odor-evoked postsynaptic calcium signals and CBF responses. We conclude that activation of postsynaptic glutamate receptors and rises in dendritic calcium are major steps for neurovascular coupling in olfactory bulb glomeruli.

Key words: two-photon microscopy; olfactory bulb; neurovascular coupling; field potential; mitral cell; blood flow

\section{Introduction}

In humans, most noninvasive brain imaging techniques assess neuronal activation from measurement of hemodynamic changes. However, the molecular and cellular mechanisms underlying the neurovascular coupling are not fully understood (for review, see Villringer and Dirnagl, 1995; Magistretti et al., 1999; Attwell and Iadecola, 2002; Logothetis and Pfeuffer, 2004; Lauritzen, 2005). Although there is a general consensus that neuronal activation is tightly correlated to cerebral blood flow (CBF) responses, the requirement for postsynaptic activation in the generation of vascular responses is still under debate (Mathiesen et al., 1998; Yang and Iadecola, 1998; Nielsen and Lauritzen, 2001; Gsell et al., 2006; Gurden et al., 2006, Hoffmeyer et al., 2006) (for review, see Logothetis, 2003; Lauritzen, 2005).

We have previously investigated neurovascular coupling in the rat olfactory bulb using two-photon laser scanning micros-

\footnotetext{
Received July 24, 2006; revised May 2, 2007; accepted May 4, 2007.

This work was supported by the Institut National de la Santé et de la Recherche Médicale, the Ministère de I'Education Nationale de la Recherche et de la Technologie (NICO025), the Centre National de la Recherche Scientifique (CNRS), the Fondation pour la Recherche Médicale (ICP20001222128), and the Région lle de France (Sesame program). Emmanuelle Chaigneau, Jérôme Lecoq, and Pascale Tiret were supported by fellowships from the Fondation pour la Recherche Médicale, the CNRS-Bourse de Doctorat pour Ingenieur and the Association Française contre les Myopathies, respectively. We thank Etienne Audinat, Jason Rothman, and Laurent Moreaux for their critical comments.

*P.T. and J.L. contributed equally to this work.

Correspondence should be addressed to Serge Charpak, Institut National de la Santé et de la Recherche Médicale U603, Laboratory of Neurophysiology, 45 rue des St Pères, 75006 Paris, France. E-mail: serge.charpak@univ-paris5.fr.

DOl:10.1523/JNEUROSCI.3141-06.2007

Copyright $\odot 2007$ Society for Neuroscience $\quad$ 0270-6474/07/276452-09\$15.00/0
}

copy (TPLSM) (Denk et al., 1990), a technique that allows simultaneous measurements of capillary red blood cell (RBC) flow (Kleinfeld et al., 1998; Chaigneau et al., 2003) and neuronal/glial cell activity (Svoboda et al., 1999; Helmchen et al., 1999; Charpak et al., 2001; Debarbieux et al., 2003; Hirase et al., 2004; Wang et al., 2006). We found that odor stimulation evoked odor-specific CBF increases in glomerular capillaries (Chaigneau et al., 2003). In addition, we observed vascular responses that apparently were confined to single glomeruli. However, in these TPLSM experiments, only a few glomeruli could be imaged, and because optical functional imaging of calcium (Wachowiak and Cohen, 2001; Spors et al., 2006), voltage (Spors and Grinvald, 2002), and intrinsic signals (Rubin and Katz, 1999; Uchida et al., 2000; Belluscio and Katz, 2001; Luo and Katz, 2001; Meister and Bonhoeffer, 2001; Yuan et al., 2002) have demonstrated that several glomeruli are often coactivated by a given odor, it remains unclear whether neurovascular coupling is regulated strictly at the level of a single glomerulus.

Here, we used calcium imaging, RBC flow measurements, and local field potential (LFP) recordings in rats and G-CaMPexpressing mice (Diez-Garcia et al., 2005) to investigate the glomerular specificity and the role of postsynaptic activity in neurovascular coupling. We show that RBC flow and local neuronal activity uncouple with repetitive stimulation and local blockade of glutamatergic synaptic transmission. Furthermore, we also demonstrate that glutamatergic synaptic transmission and rises in dendritic intracellular calcium $\left(\left[\mathrm{Ca}^{2+}\right]_{\mathrm{i}}\right)$ are required to trigger blood flow responses. 


\section{Materials and Methods}

In vivo electrophysiology and odor stimulations. Wistar rats, postnatal days 30-60 (P30-P60), were anesthetized with $1.5 \mathrm{~g} / \mathrm{kg}$ urethane intraperitoneally and held in a standard stereotaxic apparatus with ear bars. A craniotomy was performed above the two olfactory bulb hemispheres, the posterior cisterna drained, and the dura removed. G-CaMP mice (DiezGarcia et al., 2005), P30-P90, were anesthetized with a mixture of ketamine $(100 \mathrm{mg} / \mathrm{kg})$ and xylazin $(16 \mathrm{mg} / \mathrm{Kg})$ intraperitoneally and held in a custom-built apparatus by a screw fixed on the cranium. A craniotomy was performed above approximately half of one olfactory bulb. To record field potentials, a borosilicate patch pipette with a single or double barrel was filled with a standard extracellular solution containing $10 \mu \mathrm{M}$ Oregon Green and placed under visual control in labeled glomeruli using TPLSM imaging (see below). Intracellular recordings were performed using 50$100 \mathrm{Mohm}$ borosilicate glass micropipettes filled with a solution of $3 \mathrm{~mm}$ Oregon Green-BAPTA-1 in $2 \mathrm{M}$ K-acetate, pH 7.2. The dye was injected with a continuous hyperpolarizing current of $\sim 0.2-0.5 \mathrm{nA}$ for $10-30$ min. In most recordings, a $100-\mu \mathrm{m}$-thick glass coverslip was placed over the bulb, fixed on the cranium, and the space below filled with a $3 \%$ agar solution. A hole in the agar was created and the coverslip omitted during experiments in which the dorsal bulb was superfused with drugs. Electrophysiological signals recorded with a Neurodata amplifier (Cygnus Technology, Delaware Water Gap, PA) were digitized and stored on a personal computer (Digidata 1322 A, Clampex 9; Molecular Devices, Menlo Park, CA). These signals were simultaneously acquired and synchronized to images. Odors were applied for 1-4 s with a custom-built olfactometer. The olfactometer delivered a constant flow of humidified air on the rat nose. For odor application, this flow was diverted through the glass odor reservoirs by electrically triggered electrovalves. Teflon tubing was used from the odor reservoir to the nose to minimize odor contamination. C2-8 aldehydes, ketones, esters, alcohols, and carboxylic acids were used as odorants. Odor concentrations that ranged from $0.002-5 \%$ (taking into account values of saturated vapor pressure) are indicated in the figures when different odors or odor concentrations are compared. The temperature of the animal was monitored with a rectal thermometer and maintained at $37^{\circ} \mathrm{C}$ with a feedback controlled heating blanket (Harvard Apparatus, Holliston, MA). Occasionally blood $\mathrm{PO}_{2}$, $\mathrm{PCO}_{2}, \mathrm{pH}$, and electrolytes were controlled using a RapidLAB 348 analyzer from Bayer (Wuppertal, Germany).

In vivo TPLSM imaging. Axon terminals from the olfactory nerve were labeled with Oregon Green dextran with a molecular weight (MW) of 10 $\mathrm{kDa}$ using the method developed by Wachowiak and Cohen (2001). To label vessels, a bolus of $70 \mathrm{kDa}$ Texas Red dextran was injected intravenously through a catheter placed in the femoral vein. Dyes were excited and imaged using a custom two-photon laser scanning microscope (Charpak et al., 2001). Images of neurons (Oregon Green-BAPTA-1), olfactory nerve terminals (Oregon Green dextran; MW, $10 \mathrm{kDa}$ ), extracellular pipettes (Oregon Green) and blood plasma (Texas Red dextran; MW, $70 \mathrm{kDa}$ ) were simultaneously acquired on two channels separated using a dichroic mirror (cutoff wavelength, $560 \mathrm{~nm}$ ). An $880 \mathrm{~nm}$ excitation beam from a femtosecond Ti:Sapphir laser (10 W pump; Coherent, Santa Clara, CA) was focused onto neurons and capillaries using a $63 \times$ Leica (Nussloch, Germany) water-immersion objective. Galvanometric scanners (Cambridge Technology, Cambridge, MA) controlled by home-built electronics and software (LabView) were used to acquire repetitive single-line scans at $\sim 2000$ lines/s or images from subregions of the field of view at rates up to 20 frames/s. For $\left[\mathrm{Ca}^{2+}\right]_{\mathrm{i}}$ measurements, normalized fluorescence changes were calculated as follows: $\Delta F / F=$ $\left(F_{n}-F_{0}\right) /\left(F_{0}\right)$, where $F_{n}$ is the background corrected average fluorescence intensity within the measurement box in frame $n$, and $F_{0}$ is the background corrected intensity averaged over $3-5$ frames at the start of a sequence. In experiments in which 6-nitro-7-sulfamoylbenzo(f)quinoxaline-2,3-dione (NBQX) was applied, only $\Delta F$ was measured because NBQX modified the basal level of fluorescence. Fluorescent signals were acquired using a 12 bit analog-to-digital converter.

Applications of drugs. For local applications, one barrel of a borosilicate double barrel patch pipette was used to record the local field potential whereas the other one was filled with a standard extracellular solution containing drugs and $10 \mu \mathrm{M}$ Oregon Green. Two-dimensional projections of three-dimensional imaging stacks acquired through the glomerular layer (GL) were used to estimate glomerular boundaries (Chaigneau et al., 2003). During pressure injections, the laser power was increased to follow, as best as possible, the spatial diffusion of the fluorescent solution. The extent of drug diffusion was impossible to determine because we detected diffusion of the dye and not that of the drug.

Superfusion of glutamate antagonists over the dorsal bulb was achieved as follows: in rat experiments, agar was omitted from one part of the olfactory bulb surface uncovered by the craniotomy. In mouse experiments, agar was completely omitted. To block synaptic transmission, a $250 \mu \mathrm{l}$ drop of concentrated drugs (see text) diluted in saline was applied on the bulb surface.

$R B C$ velocity analysis. Line scans were acquired along the longitudinal capillary axis. Unlabeled RBCs appeared as tilted dark shadows on a bright fluorescent plasma background. The values of the velocities were calculated using algorithms based on Kleinfeld et al. (1998). The velocities of the RBCs were inversely proportional to the tangent of the shadow angle. Images were pretreated using $5 \times 5$ median and low-pass filters and subdivided into brief images $I(n)$ of $100-200$ ms duration. The average velocity $v(n)$ of RBCs in $I(n)$ was then calculated as follows: (1) each image $I(n)$ was rotated by an incremental angle $\alpha$, (2) a singular value decomposition was performed on each rotated image, (3) the $\alpha$ value for which we obtained the greatest first singular value provided the average angle of the RBC shadow in $I(n),(4) v(n)$ was calculated as $v(n)=$ $1 / \tan (\alpha)$. To measure changes in $\mathrm{RBC}$ velocity, the value at rest was determined as the mean RBC velocity before odor inhalation ( $5 \mathrm{~s}$ ) and the value during stimulation as the mean $\mathrm{RBC}$ velocity at the response maximum ( $3 \mathrm{~s})$. The onset of the vascular response was defined as the moment when two successive values were larger than twice the resting velocity $\mathrm{SD}$. In the entire study, average values are expressed as mean \pm SEM.

\section{Results}

\section{Odor-evoked LFP responses in single rat glomeruli}

Previous studies have shown that LFP signals are correlated to blood flow responses. Hence, we first investigated in the rat $(n=$ 25) which component of the odor-evoked LFP response was generated locally, within single glomerulus boundaries. Extracellular recording pipettes filled with a fluorescent marker (10 $\mu \mathrm{M}$ Oregon Green) were placed under visual control at various depths in olfactory bulb superficial layers (see Materials and Methods), after which $\sim 15-20$ odorants per experiment were screened to obtain an odor response in the recorded glomerulus. In glomeruli, odors evoked various types of LFP responses (Fig. $1 A, B, D, E)$. Figure $1 A$ shows the most common case in which odor inhalation induced repetitive rapid negativities locked to the $2 \mathrm{~Hz}$ respiration frequency. The LFP response was strongly reproducible from trial to trial (Fig. $1 A$ ). Furthermore, once the recording electrode was lowered a few tens of micrometers into the external plexiform layer (EPL), the LFP response drastically changed, and exhibited a long-lasting negativity that had no rapid repetitive negativities (Fig. $1 B$ ). Sharp transitions of LFP responses between the GL and EPL were observed with all types of odor responses (see inset): the initial rapid negativity and part of the slow negative component systematically disappeared in the upper part of the EPL. Note that such LFP response profiles strongly differed from those previously observed with olfactory nerve stimulation (Fig. 1C) (Martinez and Freeman, 1984; Aroniadou-Anderjaska et al., 1999), in which the main component of the negativity was present in both the GL and most of the EPL, fully reversed below the mitral cell layer, and involved granule cell activation. The depth profiles of odor-evoked LFP responses thus suggest that respiration-locked rapid negativities were generated in the glomerular layer.

To investigate the lateral spread of LFP responses, we used two 
A

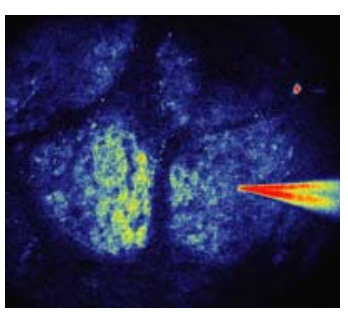

Almond

GL

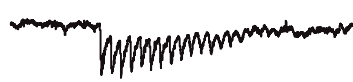

GL

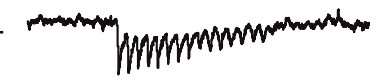

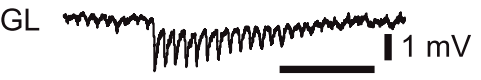

GL

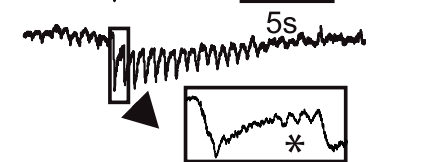

D

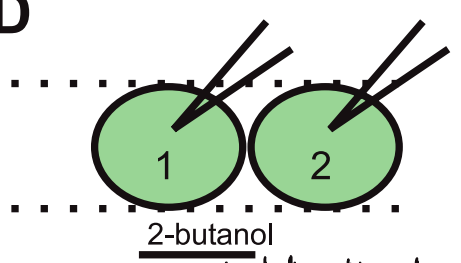

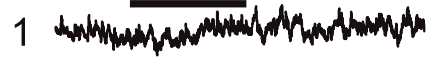

2 manth

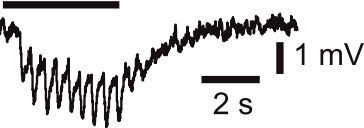

B
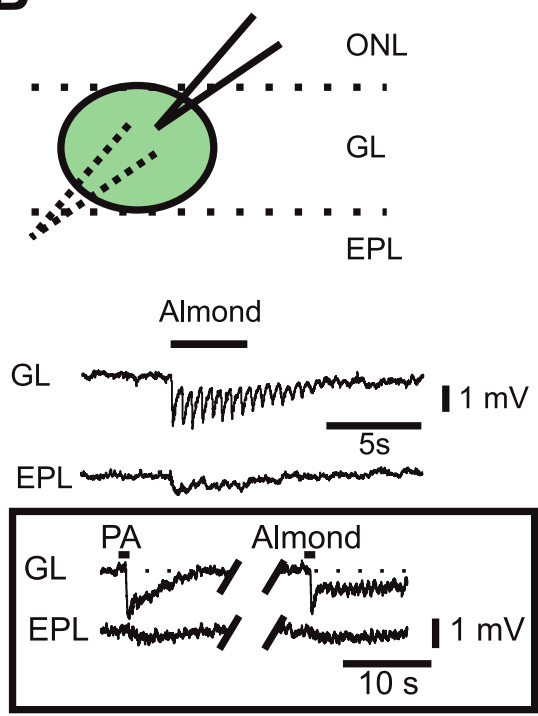

E
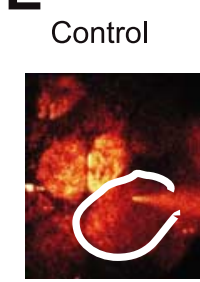

Limonene

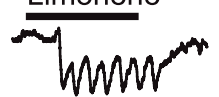

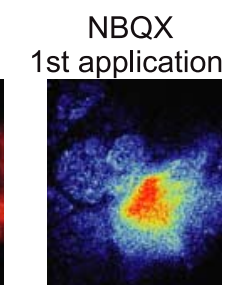

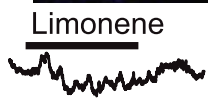

Recovery $6.5 \mathrm{~min}$
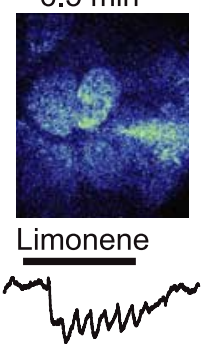

C

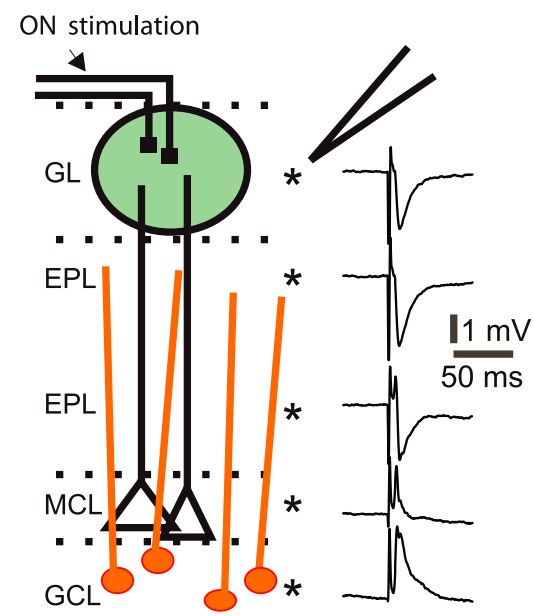

Figure 1. Odor stimulation evokes an LFP response specific to a single glomerulus. $\boldsymbol{A}$, The field potential recording pipette (filled with Oregon Green), was precisely placed in the center of the labeled glomerulus under visual control using TPLSM. In the GL, odor- evoked LFP responses that consisted of rapid and repetitive negativities locked to respiration. Note that LFP responses evoked by four successive applications of benzaldehyde (0.5\%) were very similar. Occasionally $\beta$ oscillations were recorded (inset, star). $\boldsymbol{B}, 0$ dor-evoked fast negativities were exclusive to the glomerular volume. Unlike the field potential negativity evoked by nerve stimulation ( $($ ), odor-evoked fast negativities (same as in $\boldsymbol{A}$ ) disappeared in the EPL a few tens of micrometers below the GL, leaving a slow and long-lasting negativity. Inset shows another recording in which brief application of two different odors [almond, $0.5 \%$ and propionic acid (PA), $0.3 \%$ ] evoked rapid negativities followed by slower ones of various shapes. Rapid negativities also disappeared, and the slower ones diminished in the EPL. C, Depth profile of LFP responses to olfactory nerve stimulation. $D$, LFP responses to 2-butanol (0.5\%) were glomerular-specific and showed little volume conduction. E, Glutamate receptor antagonist NBQX (250 $\mu \mathrm{m}$ dissolved in fluorescent saline) blocked LFP responses to limonene (0.4\%). TPLSM was used to image drug diffusion within glomerulus boundaries. Partial (first application) and full block (second application) occurred within seconds after application. ONL, Olfactory nerve layer; $M C L$, mitral cell layer; GCL, granule cell layer.

other approaches. First, the recording electrode was successively placed in two neighboring glomeruli, and LFP responses were tested for the same odor $(n=12$ animals). Figure $1 D$ illustrates that 2-butanol evoked rapid negativities in one glomerulus, but had no effect in the next glomerulus, indicating that volume transmission of LFP responses was limited when a single glomerulus was activated. Second, we recorded odor responses using double barrel recording electrodes (one barrel to record the LFP and one to pressure-apply NBQX and D-AP5, antagonists of glutamate AMPA, and NMDA receptors, respectively). Localized application of NBQX alone, or with D-AP5 (250 and $500 \mu \mathrm{M}$ respectively, $15-30 \mathrm{~s}, n=11$ animals) fully, reversibly, and reproducibly blocked odor-evoked LFP rapid negativities (Fig. $1 E$, see Fig. $4 A-C$ ). Note that although our methods ensured that drugs diffused within glomerular boundaries, they did not eliminate a possible diffusion outside these boundaries (see Materials and Methods). Together, these results suggest that LFP negativities are good indicators of local neuronal postsynaptic activation.
Odor-evoked LFP negativities are correlated to mitral/tufted cell dendritic tuft depolarization and accompanied by a capillary increase in blood flow

We further examined the nature of the cells generating the odorevoked LFP in glomeruli. Postsynaptic activation after an odor involves two types of postsynaptic cells in glomeruli: mitral/ tufted cells and periglomerular cells. Although mitral/tufted cells are outnumbered by a factor of $\sim 20$ by juxtaglomerular cells within a glomerulus, they are more likely to participate in the generation of odor-evoked LFP negativities because they are organized in a "vertical open field" configuration, as opposed to juxtaglomerular cells (Rall and Shepherd, 1968). The rapid LFP transition observed during odor stimulation would then be explained by the fact that our recordings were performed in the lateral or the medial dorsal olfactory bulb and the recording electrode axis was nearly perpendicular to the direction of activated apical dendrites and thus perpendicular to the dipole axis. To investigate the role of mitral/tufted cells in the generation of 
A
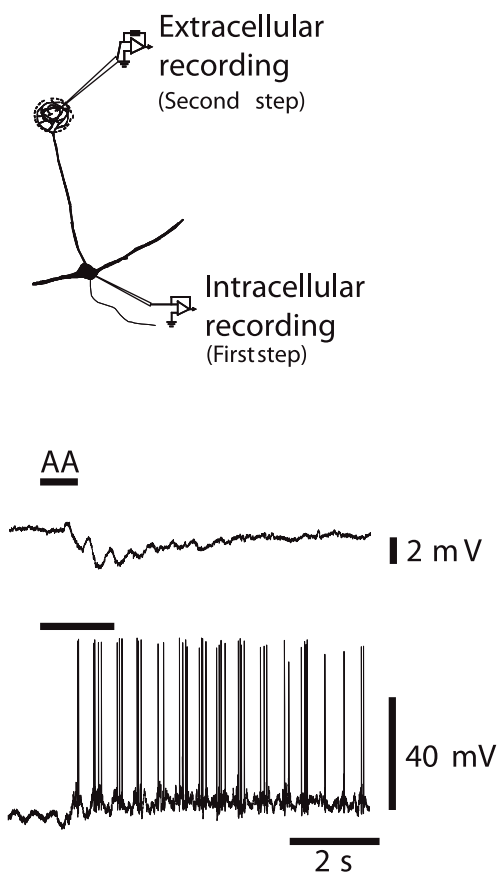

B1

Firststep
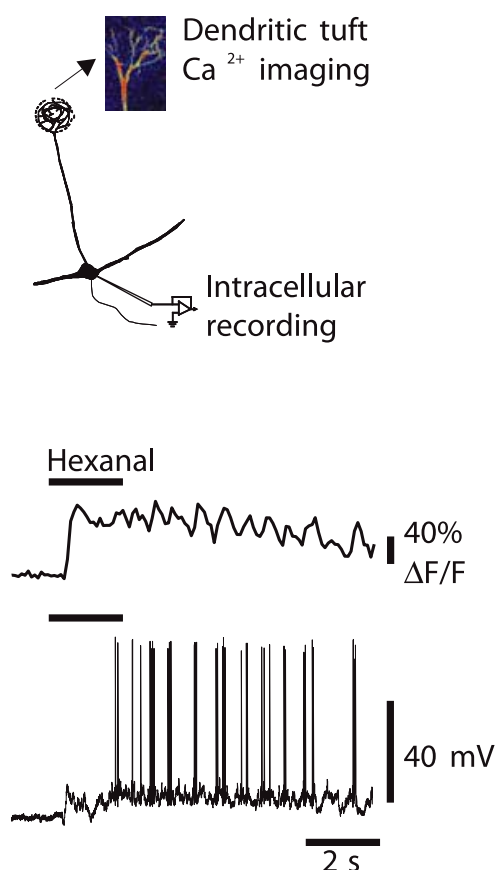

B2

\section{Second step}
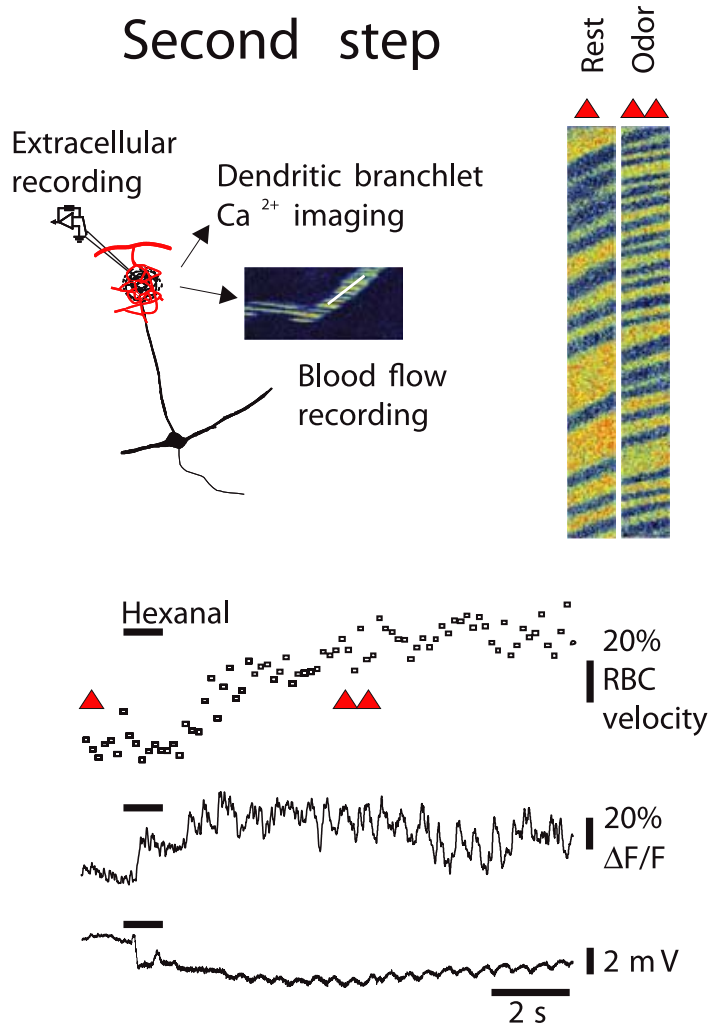

Figure 2. LFP responses are correlated to principal cell activation and associated with a local increase in blood flow. A, A mitral cell that was impaled in the soma, labeled with Oregon Green BAPTA-1, and imaged with TPLSM. This cell fired a burst of action potentials on odor inhalation [isoamyl acetate (AA) at $0.6 \%$ ]. After the micropipette was withdrawn, an extracellular pipette was placed in the labeled glomerulus and used to record the LFP response. LFP negativities were locked to respiration as action potential bursts. B1, In another cell, odor (hexanal 1.2\%) evoked a large

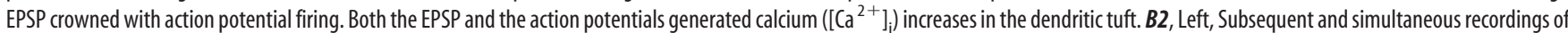
tuft $\left[\mathrm{Ca}^{2+}\right]_{\mathrm{i}}$, LFP, and RBC velocity revealed that mitral cell activity underlies LFP responses and is associated with an increase in RBC velocity. Right, Raw data of blood flow recordings at the time indicated by red triangles in the graphs. Note that $\left[\mathrm{Ca}^{2+}\right]_{i}$ measurements were performed using movie acquisition (B1) or with line-scan acquisition, allowing simultaneous measurement of RBC velocity (B2).

LFPs, we successively recorded mitral/tufted cells and LFP responses to odor (Fig. 2). In the first step of the experiment, four principal cells were intracellularly recorded with micropipettes containing $\mathrm{Ca}^{2+}$-sensitive dye (Oregon Green BAPTA-1) and their responses to odor stimulation recorded during the time necessary for the dye to diffuse to the apical dendritic tuft. TPLSM was then used to determine the location of the tuft and measure its $\left[\mathrm{Ca}^{2+}\right]_{\mathrm{i}}$ dynamics in response to odor stimulation. In the second step of the experiment, the intracellular pipette was withdrawn and an extracellular recording micropipette was placed in the glomerulus containing the labeled tuft. As Figure 2 shows, LFP responses perfectly mirrored the activation of principal cells: odor stimulation evoked synaptic depolarizations and action potential discharges locked to the respiration frequency; mitral cell membrane depolarizations also corresponded to LFP negativities. Both excitatory postsynaptic potentials and backpropagating action potentials (data not shown, but see Charpak et al., 2001; Debarbieux et al., 2003) generated calcium $\left(\left[\mathrm{Ca}^{2+}\right]_{\mathrm{i}}\right)$ increases in the dendritic tuft. Dendritic $\left[\mathrm{Ca}^{2+}\right]_{\mathrm{i}}$ recordings allowed for monitoring the stability of odor response, and similar $\left[\mathrm{Ca}^{2+}\right]_{\mathrm{i}}$ increases were observed when the electrical responses were recorded with intracellular (Fig. 2 B1) or later with extracellular recording electrodes (Fig. 2 B2). Overall, these results demonstrate that glomerular odor-evoked LFP responses are correlated to the activity of principal cells projecting to the glomerulus. However, the precise weight of their contribution to LFPs as op- posed to the juxtaglomerular contribution (Karnup et al., 2006) remains to be established.

We also found that local neuronal activation was associated with vascular responses. RBC flow increase followed LFP response (64 rats), and, in five rats in which intracellular recordings were combined with flow measurements, vascular responses lagged behind EPSP onset by a mean delay of $1.9 \pm 0.1 \mathrm{~s}$ (mean $\Delta \mathrm{RBC}$ increase, $39 \pm 5 \% ; 27$ odor applications; measurements were performed in capillaries that were intermingled with tuft dendritic branchlets). Finally, by combining LFP and RBC velocity measurements, we verified that both neuronal responses [quantified as the summation of LFP rapid negativities ( $\Sigma$ LFP)] and vascular responses increased accordingly when the duration of odor stimulation was doubled ( $\Sigma$ LFP increased from $2.0 \pm 0.3$ to $3.9 \pm 0.9 \mathrm{mV}$ and $\mathrm{RBC}$ velocity from $29 \pm 7$ to $55 \pm 10 \%$; $n=$ 7 ; $p<0.03$ and $p<0.02$, respectively; interstimulus interval, 4 $\min )$.

\section{Vascular and neuronal responses on repetitive odor stimulation}

Having characterized LFPs as indicators of glomerulus-specific neuronal activity, we examined the reproducibility of vascular responses, a necessary step before the application of drugs that modulate synaptic transmission. LFP and vascular responses were simultaneously measured when odor was repetitively applied at first every $4 \mathrm{~min}$ and then every minute. In six of six rats, 
A
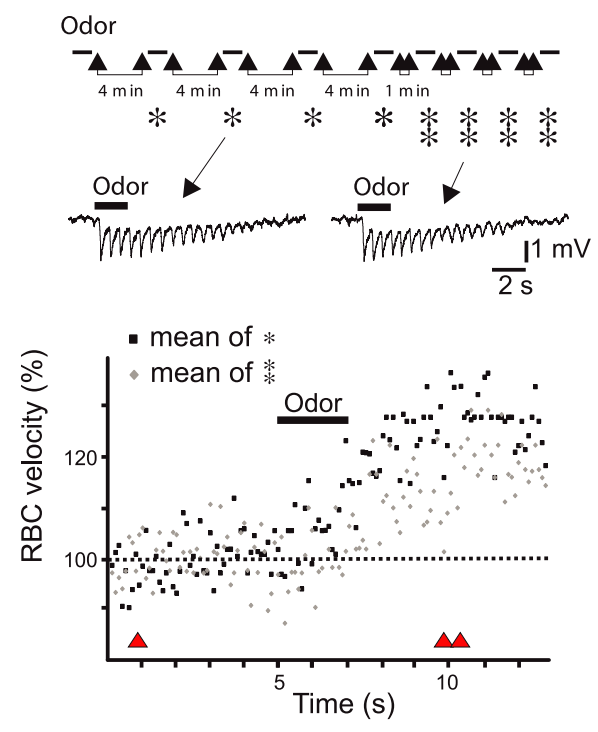

Figure 3. LFP and vascular responses uncouple on repetitive odor stimulation. $\boldsymbol{A}$, Top, Experimental protocol: benzaldehyde (0.5\%) was repetitively applied every $4 \mathrm{~min}$ (single star) and every $1 \mathrm{~min}$ (double stars). LFP responses remained stable with both interstimulus intervals (single traces are illustrated). In contrast, vascular responses decreased with 1 min interstimulus intervals. Averages of four vascular responses recorded with 4 (in black) and 1 (in gray) min interstimulus intervals are illustrated. Bottom, Single and double triangles indicate the times at which raw data in $\boldsymbol{B}$ are extracted. $\boldsymbol{B}$, Raw data of RBC flow recordings obtained before odor (single triangle) and during odor (double triangle).

vascular responses significantly decreased when the frequency of odor stimulation increased: odor-evoked RBC velocity changes decreased from $31 \pm 7$ to $22 \pm 6 \%$ when interstimulus intervals decreased from 4 to $1 \mathrm{~min}$, respectively $(n=6$; $p<0.05)$. In contrast, LFP responses, quantified as the summation of rapid negativities, were the same for both frequencies of odor stimulation ( $\Sigma$ LFP, $7 \pm 1.7$ to $6.9 \pm 1.4 \mathrm{mV}$ ) (interstimulus intervals of 4 and 1 min, respectively; $n=6 ; p=0.7$ ). A detailed example is shown in Figure 3. These results prompted us to use interstimulus intervals of 4 min to trigger maximal vascular responses.

\section{Regulation of blood flow involves several glomeruli}

We first investigated the role of postsynaptic activation in neurovascular coupling by using double-barrel micropipettes to focally apply antagonists of glutamatergic synaptic transmission while measuring both LFP and vascular responses (Fig. 4A,B). Focal application of antagonists of glutamate ionotropic receptors either alone $(250 \mu \mathrm{M}$ NBQX and $500 \mu \mathrm{M}$ D-APV diluted in fluorescent saline), or combined with an antagonist of group I glutamate metabotropic receptors (mGluRs) [250 $\mu \mathrm{M}$ 2-methyl-4carboxyphenyglycine (LY367385)], reversibly and reproducibly blocked synaptic transmission, but left vascular responses unchanged: odor-evoked RBC velocity increase was $29 \pm 5 \%$ in the presence of NBQX and D-APV versus $30 \pm 4 \%$ in control conditions $(n=5)$ and $41 \pm 14 \%$ in the presence of NBQX, D-APV, and LY367385 versus $38 \pm 13 \%$ in control conditions $(n=3)$. Because olfactory nerve stimulation (Heinbockel et al., 2004; Saint Jan and Westbrook, 2005) activates ionotropic and mGluR1 glutamate receptors of principal cells, these results demonstrate that neurovascular coupling within a glomerulus is independent of the activation of the related mitral/tufted cells. Note that application of NBQX, D-APV, and LY367385 at such con- centrations also blocked most of the excitatory synaptic activation of the periglomerular cells. Two mechanisms could explain these results: first, within a single glomerulus, vascular responses are independent of postsynaptic activation of neurons and are instead triggered by glutamate release and activation of astrocytes (Takano et al., 2005). Second, and more likely, vascular responses are not perfectly glomerular-specific, and the local RBC velocity changes observed during local inhibition of synaptic transmission are triggered by the coactivation of neighboring glomeruli (Rubin and Katz, 1999; Uchida et al., 2000; Belluscio and Katz, 2001; Luo and Katz, 2001; Meister and Bonhoeffer, 2001; Wachowiak and Cohen, 2001; Spors and Grinvald, 2002; Yuan et al., 2002; Spors et al., 2006). To investigate whether local activation of astrocytes by glutamate was sufficient to trigger vascular responses, we blocked glutamate release with local injections of tetrodotoxin (TTX). As expected (Fig. 4C,D), intraglomerular applications of $1 \mu \mathrm{M}$ TTX fully blocked the LFP responses. However, they neither blocked nor affected vascular responses (RBC velocity increased by $28 \pm 4 \%$ in control and by $33 \pm 7 \%$ in the presence of TTX; $n=6 ; p>0.4$ ). In contrast, we observed a clear depression of vascular responses when TTX was applied at a higher concentration $(5 \mu \mathrm{M})$ and with spatially larger applications (i.e., the dye diffusing outside single glomerular boundaries) (RBC velocity increased by $27 \pm 4 \%$ in control and by $6 \pm$ $3 \%$ in the presence of TTX; $n=3 ; p<0.01$ ). These results are consistent with the idea that in our experimental conditions, vascular responses are controlled by cooperation of several glomeruli. Therefore, the role of postsynaptic activation in triggering neurovascular coupling cannot be definitely established using local blockade of synaptic transmission.

\section{Postsynaptic activation modulates vascular responses}

To interfere with synaptic transmission more widely, we only partially covered the dorsal bulb with agar and superfused glutamate antagonists onto the bulb surface. Removing agar decreased the preparation stability. For this reason, we were only able to obtain stable two-photon measurements of CBF in four of 11 rats. In these four cases, high concentrations of glutamate ionotropic receptor antagonists (NBQX, 250-500 $\mu \mathrm{M}$; D-AP5, 0.5-1 $\mathrm{mM}$ ) induced a modest but significant decrease of odor-evoked LFP and RBC flow responses ( $\Sigma$ LFP decreased from $1.68 \pm 0.3$ to $0.96 \pm 0.38 \mathrm{mV}, p=0.038$; and changes in RBC velocity decreased from $0.36 \pm 0.02$ to $0.19 \pm 0.02 \mathrm{~mm} / \mathrm{s}, p=0.022$ ). Although these results clearly indicate that postsynaptic activation modulates vascular responses, we looked for a more reliable model for the following reasons: (1) because of movement problems, these imaging experiments were extremely difficult to perform, (2) the blockade of LFPs by glutamate antagonists was not complete and in some cases rapidly reversible, probably resulting from drug washout by blood flow, (3) higher NBQX concentrations decreased the signal-to-noise ratio of fluorescent signals and thus could not be used. We thus further investigated the role of postsynaptic activation in the mouse where the olfactory nerve layer is thin and glutamate receptor antagonists, applied on the bulb surface, can be expected to reach the glomerular layer more readily than in the rat and thus block synaptic transmission over a larger portion of the dorsal olfactory bulb.

\section{Odor induces $\mathrm{Ca}^{2+}$ fluorescence increases in the glomerular layer from G-CaMP2 mice}

To facilitate the detection of responsive glomeruli, we recorded odor responses in the G-CaMP2 transgenic mouse (Diez-Garcia et al., 2005, 2007). This mouse has been successfully used to re- 
A
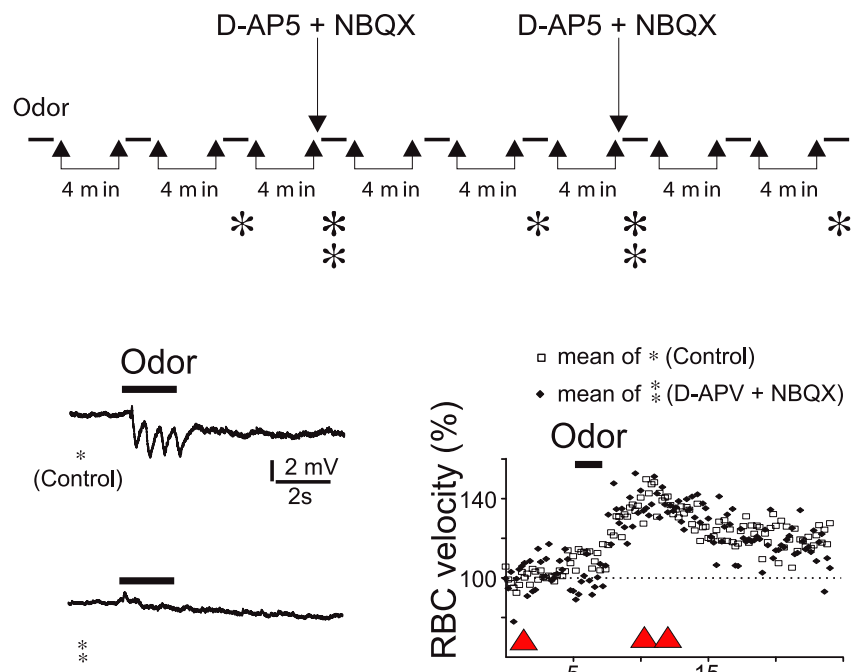

$(D-A P V+N B Q X)$
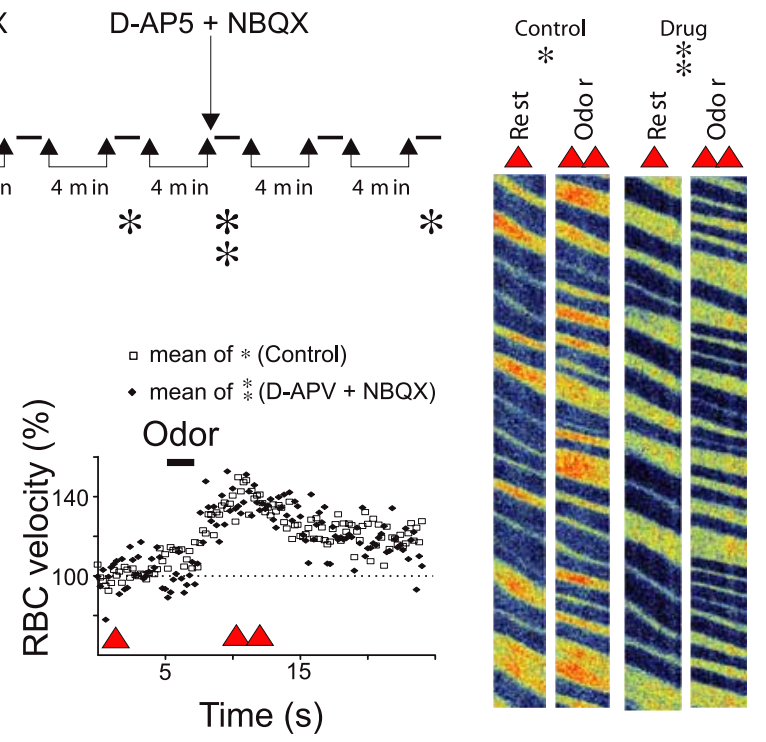

C
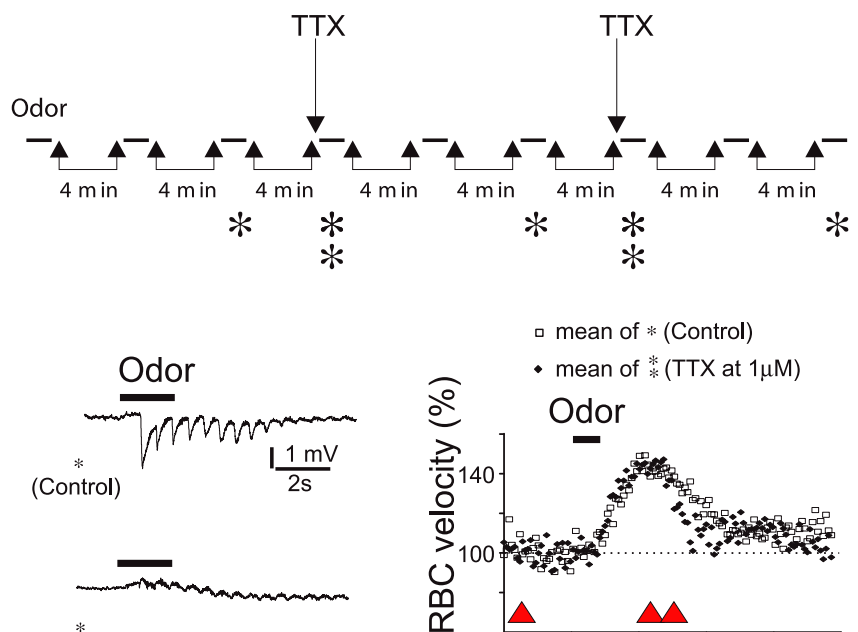$$
\text { (TTX } 1 \mu \mathrm{M})
$$
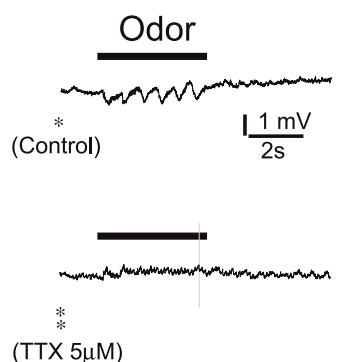

(TTX $5 \mu \mathrm{M})$
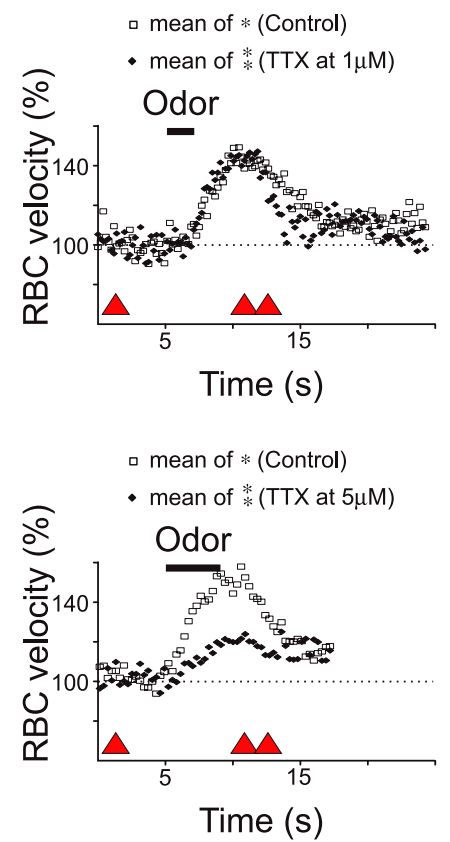

B

D
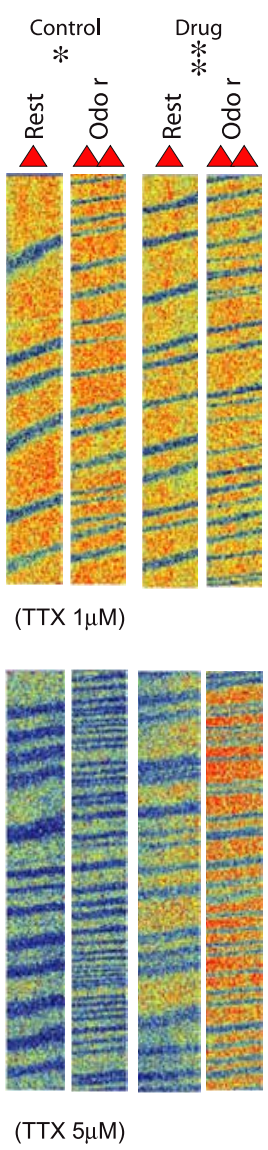

Figure 4. A, Blockade of local postsynaptic activity does not affect the vascular responses. Top, Experimental protocol: Hexanal (1.2\%) was repetitively applied every $4 \mathrm{~min}$ in the control condition and $30-60 \mathrm{~s}$ after intraglomerular applications of glutamate ionotropic receptor antagonists (250 $\mu \mathrm{m}$ NBQX, $500 \mu \mathrm{m}$ D-APV diluted in fluorescent saline). TPLSM was used to image drug diffusion within glomerulus boundaries. Glutamate antagonists reversibly and reproducibly blocked LFP negativities but left vascular responses to hexanal unchanged. Single trial LFPs and average vascular responses are illustrated. Single and double triangles indicate the times at which raw data in $\boldsymbol{B}$ are extracted. $\boldsymbol{B}$, Raw data of $\mathrm{RBC}$ flow recordings obtained before odor (single port neuronal activity in granule cells from the cerebellum, where G-CaMP2 fluorescence increases with neuronal $\left[\mathrm{Ca}^{2+}\right]_{\mathrm{i}}$. We first tested whether this mouse could be used to report glomerular activation. In 12 of 12 mice, we observed that G-CaMP2 was expressed in mitral cells (Fig. 5AI, arrows point to two activated mitral cell apical dendrites) and in some periglomerular cells (Fig. 5AII,AIII, arrowheads). In each mouse, odor triggered odorant-specific increases in glomerular fluorescence, reflecting a $\mathrm{Ca}^{2+}$ increase in activated postsynaptic cells (for the effect of glutamate antagonists, see below). Responses to high odor concentrations were first investigated in several fields of view from the dorsal bulb, until fluorescence signals were reliably obtained. Odors were then compared at diluted concentrations (0.01-1.3\%). Figure $5 B$ shows different $\mathrm{Ca}^{2+}$-signal increases of three neighboring glomeruli in response to three odorants. Note that in these examples, as well as in Figure $5 C$, $\mathrm{Ca}^{2+}$ responses were locked to respiration, a rhythmic activity reminiscent of what is observed in LFP (see above) and mitral cell responses (Charpak et al., 2001; Debarbieux et al., 2003). Dilution of the odor concentration decreased the number of activated neighboring glomeruli (Fig. $5 C$ ) and increased the response delay, a phenomenon that was also observed in LFP responses (data not shown). The properties of these odor-evoked fluorescence responses suggest that G-CaMP2 mice can be used to study the role of postsynaptic activity in neurovascular coupling. In the rest of the study, we used odor concentrations that activated one to three glomeruli in a $400 \times 400 \mu \mathrm{m}$ field of view and in this way mimicked the experimental conditions previously seen in the rat.

\section{$\longleftarrow$}

triangle) and during odor (double triangle) in control condition (single star) and in the presence of glutamate antagonists (double star). C, Blockade of local glutamate release does not affect vascular responses. Top, Local application of $1 \mu \mathrm{m}$ TTX (diluted in fluorescent saline) fully blocked LFP responses but did not affect vascular responses to ethyl propionate $(0.005 \%)$. Bottom, Application of a higher concentration of TTX (5 $\mu \mathrm{m}$ ) outside glomerular boundaries decreased vascular responses to hexanal (1.2\%). In each case, single trial LFPs and average vascular responses are illustrated. Single and double triangles indicate the times at which raw data in $\boldsymbol{D}$ are extracted. D, Raw data of RBC flow recordings obtained before odor (single triangle) and during odor (double triangle) in control condition (single triangle) and in the presence of 1 $\mu \mathrm{M}$ TTX (top) and $5 \mu \mathrm{M}$ TTX (bottom). 
Postsynaptic activation of glomerular dendrites is required to trigger vascular responses in G-CaMP2 mice

In seven of 10 mice (no agar), we were able to measure CBF in a single capillary while simultaneously recording G-CaMP2 fluorescence in the nearby glomerular neuropil. To do this, long line scans with an angle were acquired (Fig. 6A), drawing the first part of the line along the capillary, and the second part through the neuropil (fluorescence of $\mathrm{CBF}$ and $\mathrm{Ca}^{2+}$ were recorded in two separate detector channels). Results of these experiments show that odor triggered a $\left[\mathrm{Ca}^{2+}\right]_{\mathrm{i}}$ increase that preceded the vascular response by 1-2 s. Furthermore, high concentrations of glutamate ionotropic receptor antagonists applied to the surface of the bulb (NBQX, 0.25-0.5 mM; D-AP5, 0.5-1 mM) decreased both odorevoked $\left[\mathrm{Ca}^{2+}\right]_{\mathrm{i}}$ and $\mathrm{RBC}$ responses $(n=6$ capillaries): $\mathrm{Ca}^{2+}$ responses, measured as $\Delta F$ (see Materials and Methods), decreased from $306 \pm 121$ to $47 \pm 26$ arbitrary units (a.u.), $p=0.03$ and $\Delta \mathrm{RBC}$ velocity decreased from $0.18 \pm 0.05$ to $0.05 \pm 0.01 \mathrm{~mm} / \mathrm{s}, p=0.03$. Notably, although the blocking effects of glutamate antagonists on $\triangle \mathrm{RBC}$ velocity and $\mathrm{Ca}^{2+}$ responses were correlated, they were also highly variable, ranging from 37 to $95 \%$ for $\triangle \mathrm{RBC}$ velocity and from 52 to $100 \%$ for $\mathrm{Ca}^{2+}$ responses. Coapplication of LY367385 (500 $\mu \mathrm{M})$ with ionotropic receptor antagonists had a similar effect on $\mathrm{CBF}$ (in three capillaries, $\triangle \mathrm{RBC}$ velocity decreased from $0.16 \pm 0.03$ to $0.08 \pm 0.02$ $\mathrm{mm} / \mathrm{s} ; p=0.05)$. Hence, we conclude that if glutamate ionotropic receptors are principally located on glomerular dendrites (see Discussion), their activation and the subsequent dendritic $\left[\mathrm{Ca}^{2+}\right]_{\mathrm{i}}$ increase are likely to play a major role in triggering the vascular response.

\section{Discussion}

In the olfactory bulb, methods for detecting hemodynamic changes (e.g., blood oxygenation level-dependent functional magnetic resonance imaging (Yang et al., 1998; Xu et al., 2000; Kida et al., 2002) and TPLSM (Chaigneau et al., 2003) have clearly demonstrated that odor stimulation reproducibly activates small glomerular ensembles. However, the nature of the coupling between neuronal activation and the local glomerular vascular response has been unknown until a recent study, using intrinsic optical signals, suggested that local metabolic processing and blood flow responses are independent of postsynaptic activation (Gurden et al., 2006). Our local pharmacological results seemed initially to support this hypothesis: intraglomerular blockade of glutamate ionotropic receptors abolished odor-evoked postsynaptic responses, whether measured as LFP responses or as increases in dendritic $\left[\mathrm{Ca}^{2+}\right]_{\mathrm{i}}$, but it did not affect

A

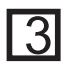

C
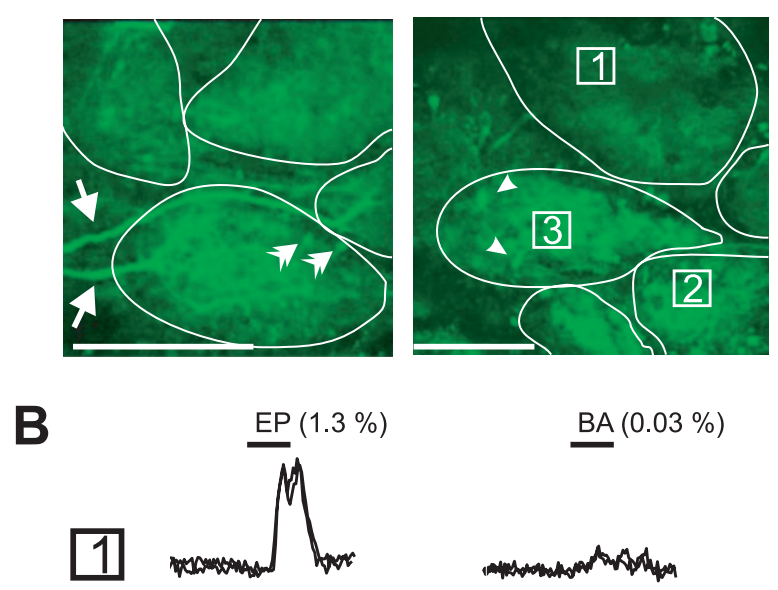

BA $(0.03 \%)$
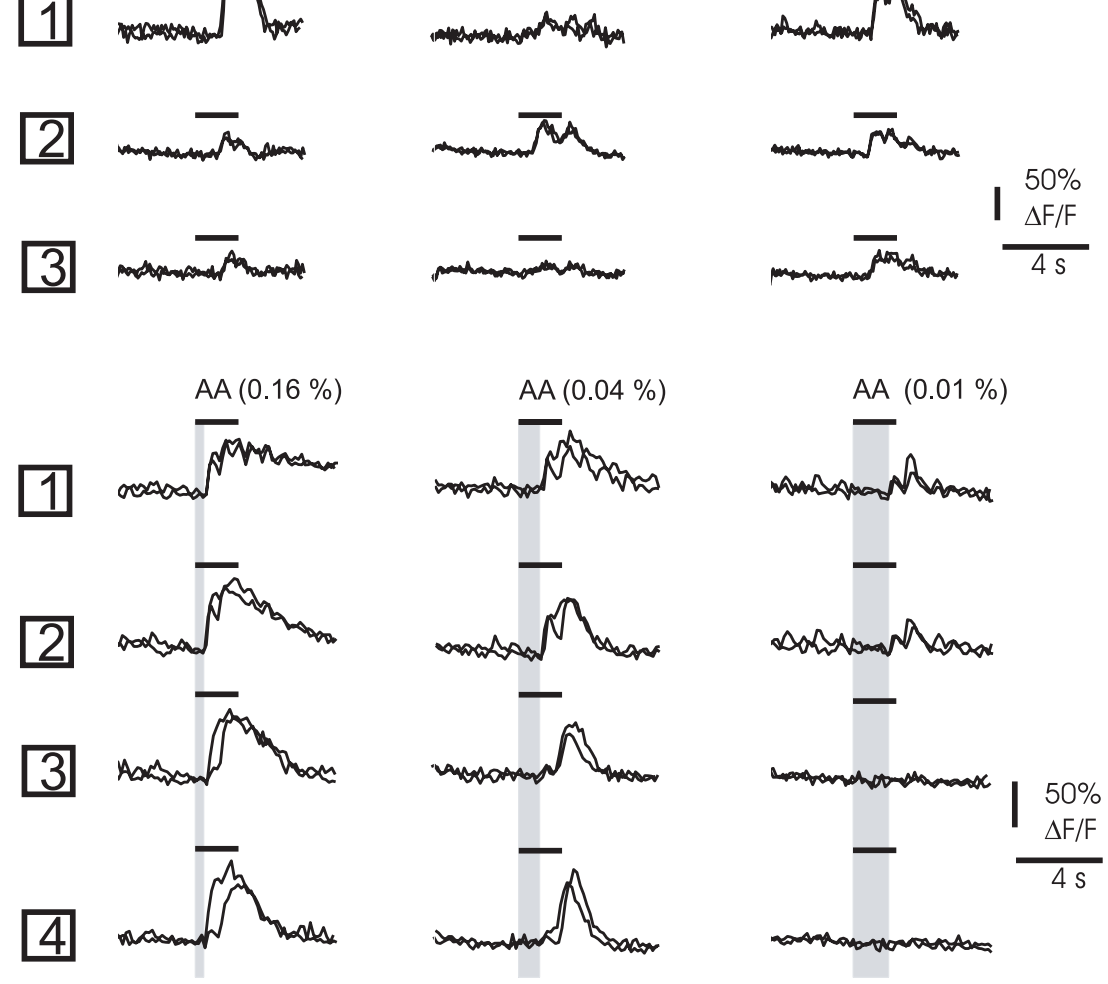

Figure 5. Odor induces $\mathrm{Ca}^{2+}$ signals in glomeruli from G-CaMP2 mice. $A$, Two-photon imaging of three fields of view obtained in the glomerular layer (glomerular contours are outlined). G-CaMP2 fluorescence is expressed in mitral cells and in some periglomerular cells: arrows point to two longitudinal mitral cell apical dendrites and double arrowheads to two apical dendrite sections $(\boldsymbol{A I})$; arrowheads point at several periglomerular cells (AII, AIII). Scale bars, $100 \mu \mathrm{m} . \mathbf{B}, 0$ dorant-dependent increases in $\mathrm{Ca}^{2+}$ fluorescence. Movies were acquired over the field of view illustrated in $A$ II with a lower spatial and higher time resolution. Responses to ethylpropionate (EP), benzaldehyde (BA), and isoamylacetate (AA) varied according to each glomerulus. For each glomerulus, responses to two odor applications are overlaid. As odor-evoked LFP responses, $\mathrm{Ca}^{2+}$ responses were occasionally locked to respiration, in particular at low odor concentration. $\mathrm{C}_{,} \mathrm{Ca}^{2+}$ responses are concentration dependent. Movies were acquired over the field of view illustrated in AIII. At a high concentration, isoamylacetate (AA) activated all glomeruli in the field of view. Only two of them responded when the odor was diluted. For each glomerulus, responses to two odor applications are overlaid. Note the increasing delay (in gray) of $\mathrm{Ca}^{2+}$ responses with odor dilution.

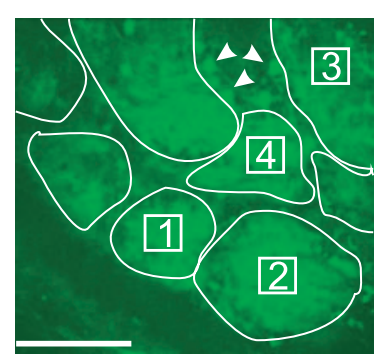

$\mathrm{AA}(0.16 \%)$

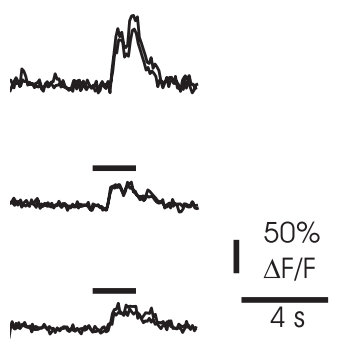


A
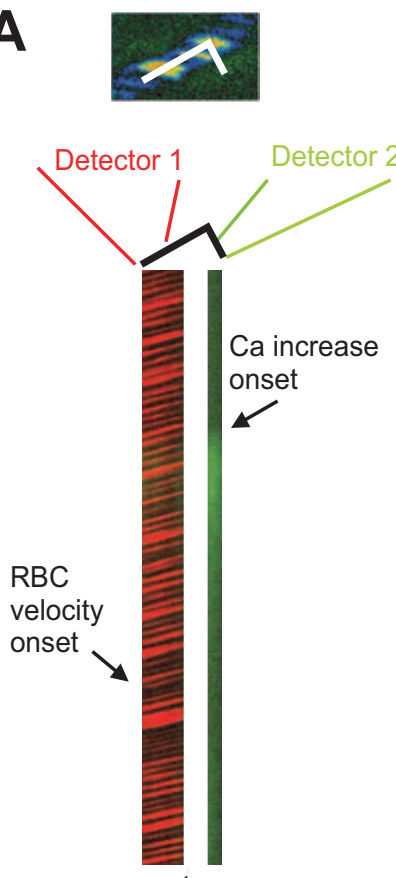

B
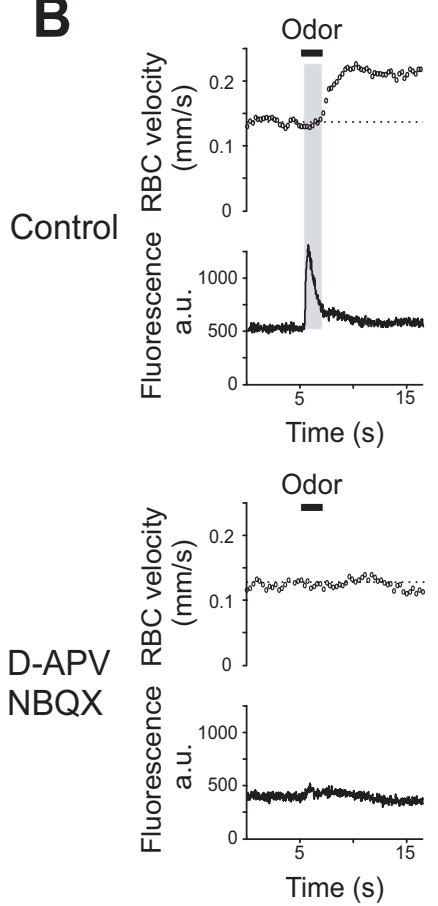

Figure 6. Postsynaptic activation of glomerular dendrites is required to trigger blood flow responses in G-CaMP2 expressing mice. A, Left, 0 dor (ethyl butyrate at $0.004 \%$ ) triggers a $\mathrm{Ca}^{2+}$ signal followed by an increase in CBF. Line scans were acquired on a segment going along the longitudinal axis of the capillary for its first part and through the neighboring neuropil for its second part. RBC velocity measurements (the first part of the line scan) were acquired on one detector and $\mathrm{Ca}^{2+}$ fluorescence (the last part of the line scan) on the second one. Right, Both neuronal and vascular responses were blocked in the presence of $250 \mu \mathrm{m} \mathrm{NBQX}$ and $500 \mu \mathrm{m}$ D-APV. Note the delay (in gray) between neuronal and vascular responses.

Because our initial experiments did not allow us to assess the role of postsynaptic activation in neurovascular coupling, we used another paradigm that allowed us to block synaptic transmission in a large portion of the dorsal bulb. Experiments using superfusion of glutamate antagonists over the olfactory bulb in rats and particularly in mice strongly supported the hypothesis that neurovascular coupling requires postsynaptic activation. G-CaMP2 mice have been previously used to report neuronal activity in the cerebellar cortex where they are exclusively expressed in granule cells: activation of parallel fibers induced $\mathrm{Ca}^{2+}$ transients that could be observed using one- or two-photon excitation imaging (Diez-Garcia et al., 2007). Here, because G-CaMP2 fluorescence was expressed mostly in mitral cells, but also in a few periglomerular cells, odorant molecules induced $\mathrm{Ca}^{2+}$ responses that principally reflected postsynaptic activation of mitral cells and shared the properties of LFP responses: $\mathrm{Ca}^{2+}$ response amplitudes were correlated to the odor concentration and to respiration frequency. Glutamate receptor antagonists either strongly reduced or fully blocked both postsynaptic $\mathrm{Ca}^{2+}$ and vascular responses in G-CaMP2 mice.

Although this set of experiments clearly showed that vascular responses required the activation of glutamate ionotropic receptors, it did not exclude the possibility that the relevant receptors are located on glial cells (for review, see Lalo, 2005, 2006). However, this is unlikely because in glomerular astrocytes, synaptically released glutamate activates only an indirect $\mathrm{K}^{+}$current resulting from the glutamatergic activation of mitral cells and a direct glutamate transporter current (Saint Jan and Westbrook, 2005). We thus propose that postsynaptic activation of glomeru- lar neurons is required to trigger vascular responses, because it has been shown in the cerebellum and the cortex (Mathiesen et al., 1998; Yang and Iadecola, 1998; Nielsen and Lauritzen, 2001; Gsell et al., 2006; Hoffmeyer et al., 2006). As mentioned by Gurden et al. (2006), it is likely that certain intrinsic optical signals maintained in the presence of glutamate antagonists may reflect changes in light scattering involving either olfactory nerve terminals or astrocytes.

In vitro brain preparations have shown several molecular mechanisms involved in the regulation of arteriolar diameter by glial cells and neurons (Zonta et al., 2003; Cauli et al., 2004; Mulligan and MacVicar, 2004; Filosa et al., 2004, 2006; Metea and Newman, 2006; Rancillac et al., 2006). Yet, the results from these in vitro preparations also raised issues, such as the absence of adequate smooth muscle resting tone and the disruption of cellular networks, which certainly will affect neurovascular coupling. Our study and that by Wang et al. (2006) show that TPLSM allows for adequate spatial and temporal resolution while studying neurovascular coupling in vivo and so demonstrates that the vascular response is tightly coupled to neuronal and glial $\left[\mathrm{Ca}^{2+}\right]_{\mathrm{i}}$. It thus becomes possible to link in vivo cellular $\left[\mathrm{Ca}^{2+}\right]_{\mathrm{i}}$ rises to the production of several compounds involved in the regulation of vessel diameters (e.g., nitric oxide or prostaglandins) (Yang and Iadecola, 1998; Lauritzen, 2005; Hoffmeyer et al., 2006; Stefanovic et al., 2007). However, our study stresses that responses to drugs, applied on the brain surface, are extremely variable and reversible, indicating the need to permanently and simultaneously control neuronal activity and blood flow at the same site. We attribute the difficulty to fully block the responses to the efficiency of drug clearance by blood flow as well as to the variability of glomeruli location in depth.

What components of odor-evoked LFP responses are generated locally? LFP rapid negativities reflect neuronal activation restricted to a single glomerular volume: over the study, hundreds of odor presentations did not evoke any LFP responses in many glomeruli. When tested between two neighboring glomeruli, odor-evoked LFP responses were clearly glomerular specific, and their transitions in space (laterally and in depth) were sharp and abolished with intraglomerular TTX application. Odorevoked LFP rapid negativities thus constitute a reliable and reproducible measure of glomerular activity. It should be noted that LFPs contained a slow component that we did not use for our analysis and that appeared to reflect only partially local activity. Which cell type generates local LFP responses? As suggested by Rall and Shepherd (1968) decades ago, LFPs are most likely generated by mitral/tufted cells that are organized in a "vertical open field" configuration as opposed to juxtaglomerular cells. In favor of this hypothesis, in this study, LFPs were tightly correlated to mitral cell activity and varied little when the recording electrode was moved within glomerulus boundaries (data not shown). Note that an LFP transition and reversal should have been observed at the border of the glomerulus if a subpopulation of juxtaglomerular cells had been activated. These results raise the general issue that physiological stimuli involve completely different neuronal networks from those activated during nerve stimulation or those occurring spontaneously in isolated glomerular layer slices (Karnup et al., 2006). For example, olfactory nerve stimulation activates a large portion of the glomerular layer, triggering a very powerful granule cell excitation that generates almost entirely the first rapid LFP negativity. In contrast, odorants usually activate only a few glomeruli, and granule cells do not participate in the glomerular fast LFP negativities. This should be 
taken into consideration when analyzing the link between the LFP responses and the vascular responses.

\section{References}

Aroniadou-Anderjaska V, Ennis M, Shipley MT (1999) Current-source density analysis in the rat olfactory bulb: laminar distribution of kainate/ AMPA- and NMDA-receptor-mediated currents. J Neurophysiol 81:15-28.

Attwell D, Iadecola C (2002) The neural basis of functional brain imaging signals. Trends Neurosci 25:621-625.

Belluscio L, Katz LC (2001) Symmetry, stereotypy, and topography of odorant representations in mouse olfactory bulbs. J Neurosci 21:2113-2122.

Cauli B, Tong XK, Rancillac A, Serluca N, Lambolez B, Rossier J, Hamel E (2004) Cortical GABA interneurons in neurovascular coupling: relays for subcortical vasoactive pathways. J Neurosci 24:8940-8949.

Chaigneau E, Oheim M, Audinat E, Charpak S (2003) Two-photon imaging of capillary blood flow in olfactory bulb glomeruli. Proc Natl Acad Sci USA 100:13081-13086.

Charpak S, Mertz J, Beaurepaire E, Moreaux L, Delaney K (2001) Odorevoked calcium signals in dendrites of rat mitral cells. Proc Natl Acad Sci USA 98:1230-1234.

Debarbieux F, Audinat E, Charpak S (2003) Action potential propagation in dendrites of rat mitral cells in vivo. J Neurosci 23:5553-5560.

Denk W, Strickler JH, Webb WW (1990) Two-photon laser scanning fluorescence microscopy. Science 248:73-76.

Diez-Garcia J, Matsushita S, Mutoh H, Nakai J, Ohkura M, Yokoyama J, Dimitrov D, Knöpfel T (2005) Activation of cerebellar parallel fibers monitored in transgenic mice expressing a fluorescent $\mathrm{Ca} 2+$ indicator protein. Eur J Neurosci 22:627-635.

Diez-Garcia J, Akemann W, Knöpfel T (2007) In vivo calcium imaging from genetically specified target cells in mouse cerebellum. NeuroImage 34:859-869.

Filosa JA, Bonev AD, Nelson MT (2004) Calcium dynamics in cortical astrocytes and arterioles during neurovascular coupling. Circ Res 95:e73-e81.

Filosa JA, Bonev AD, Straub SV, Meredith AL, Wilkerson MK, Aldrich RW, Nelson MT (2006) Local potassium signaling couples neuronal activity to vasodilation in the brain. Nat Neurosci 9:1397-1403.

Gsell W, Burke M, Wiedermann D, Bonvento G, Silva AC, Dauphin F, Buhrle C, Hoehn M, Schwindt W (2006) Differential effects of NMDA and AMPA glutamate receptors on functional magnetic resonance imaging signals and evoked neuronal activity during forepaw stimulation of the rat. J Neurosci 26:8409-8416.

Gurden H, Uchida N, Mainen ZF (2006) Sensory-evoked intrinsic optical signals in the olfactory bulb are coupled to glutamate release and uptake. Neuron 52:335-345.

Heinbockel T, Heyward P, Conquet F, Ennis M (2004) Regulation of main olfactory bulb mitral cell excitability by metabotropic glutamate receptor mGluR1. J Neurophysiol 92:3085-3096.

Helmchen F, Svoboda K, Denk W, Tank DW (1999) In vivo dendritic calcium dynamics in deep-layer cortical pyramidal neurons. Nat Neurosci 2:989-996.

Hirase H, Qian L, Bartho P, Buzsaki G (2004) Calcium dynamics of cortical astrocytic networks in vivo. PLoS Biol 2:E96.

Hoffmeyer HW, Enager P, Thomsen KJ, Lauritzen MJ (2006) Nonlinear neurovascular coupling in rat sensory cortex by activation of transcallosal fibers. J Cereb Blood Flow Metab 27:575-587.

Karnup SV, Hayar A, Shipley MT, Kurnikova MG (2006) Spontaneous field potentials in the glomeruli of the olfactory bulb: the leading role of juxtaglomerular cells. Neuroscience 142:203-221.

Kida I, Xu F, Shulman RG, Hyder F (2002) Mapping at glomerular resolution: fMRI of rat olfactory bulb. Magn Reson Med 48:570-576.

Kleinfeld D, Mitra PP, Helmchen F, Denk W (1998) Fluctuations and stimulus-induced changes in blood flow observed in individual capillaries in layers 2 through 4 of rat neocortex. Proc Natl Acad Sci USA 95:15741-15746.

Lauritzen M (2005) Reading vascular changes in brain imaging: is dendritic calcium the key? Nat Rev Neurosci 6:77-85.

Logothetis NK (2003) The underpinnings of the BOLD functional magnetic resonance imaging signal. J Neurosci 23:3963-3971.

Logothetis NK, Pfeuffer J (2004) On the nature of the BOLD fMRI contrast mechanism. Magn Reson Imaging 22:1517-1531.
Luo M, Katz LC (2001) Response correlation maps of neurons in the mammalian olfactory bulb. Neuron 32:1165-1179.

Magistretti PJ, Pellerin L, Rothman DL, Shulman RG (1999) Energy on demand. Science 283:496-497.

Martinez DP, Freeman WJ (1984) Periglomerular cell action on mitral cells in olfactory bulb shown by current source density analysis. Brain Res 308:223-233.

Mathiesen C, Caesar K, Akgoren N, Lauritzen M (1998) Modification of activity-dependent increases of cerebral blood flow by excitatory synaptic activity and spikes in rat cerebellar cortex. J Physiol (Lond) 512:555-566.

Meister M, Bonhoeffer T (2001) Tuning and topography in an odor map on the rat olfactory bulb. J Neurosci 21:1351-1360.

Metea MR, Newman EA (2006) Glial cells dilate and constrict blood vessels: a mechanism of neurovascular coupling. J Neurosci 26:2862-2870.

Mulligan SJ, MacVicar BA (2004) Calcium transients in astrocyte endfeet cause cerebrovascular constrictions. Nature 431:195-199.

Nielsen AN, Lauritzen M (2001) Coupling and uncoupling of activitydependent increases of neuronal activity and blood flow in rat somatosensory cortex. J Physiol (Lond) 533:773-785.

Rall W, Shepherd GM (1968) Theoretical reconstruction of field potentials and dendrodendritic synaptic interactions in olfactory bulb. J Neurophysiol 31:884-915.

Rancillac A, Rossier J, Guille M, Tong XK, Geoffroy H, Amatore C, Arbault S, Hamel E, Cauli B (2006) Glutamatergic control of microvascular tone by distinct GABA neurons in the cerebellum. J Neurosci 26:6997-7006.

Rubin BD, Katz LC (1999) Optical imaging of odorant representations in the mammalian olfactory bulb. Neuron 23:499-511.

Saint Jan DD, Westbrook GL (2005) Detecting activity in olfactory bulb glomeruli with astrocyte recording. J Neurosci 25:2917-2924.

Spors H, Grinvald A (2002) Spatio-temporal dynamics of odor representations in the mammalian olfactory bulb. Neuron 34:301-315.

Spors H, Wachowiak M, Cohen LB, Friedrich RW (2006) Temporal dynamics and latency patterns of receptor neuron input to the olfactory bulb. J Neurosci 26:1247-1259.

Stefanovic B, Schwindt W, Hoehn M, Silva AC (2007) Functional uncoupling of hemodynamic from neuronal response by inhibition of neuronal nitric oxide synthase. J Cereb Blood Flow Metab 27:741-754.

Svoboda K, Helmchen F, Denk W, Tank DW (1999) Spread of dendritic excitation in layer $2 / 3$ pyramidal neurons in rat barrel cortex in vivo. Nat Neurosci 2:65-73.

Takano T, Tian GF, Peng W, Lou N, Libionka W, Han X, Nedergaard M (2005) Astrocyte-mediated control of cerebral blood flow. Nat Neurosci 9:260-267.

Uchida N, Takahashi YK, Tanifuji M, Mori K (2000) Odor maps in the mammalian olfactory bulb: domain organization and odorant structural features. Nat Neurosci 3:1035-1043.

Villringer A, Dirnagl U (1995) Coupling of brain activity and cerebral blood flow: basis of functional neuroimaging. Cerebrovasc Brain Metab Rev $7: 240-276$.

Wachowiak M, Cohen LB (2001) Representation of odorants by receptor neuron input to the mouse olfactory bulb. Neuron 32:723-735.

Wang X, Lou N, Xu Q, Tian GF, Peng WG, Han X, Kang J, Takano T, Nedergaard M (2006) Astrocytic Ca2+ signaling evoked by sensory stimulation in vivo. Nat Neurosci 9:816-823.

Xu F, Kida I, Hyder F, Shulman RG (2000) Assessment and discrimination of odor stimuli in rat olfactory bulb by dynamic functional MRI. Proc Natl Acad Sci USA 97:10601-10606.

Yang G, Iadecola C (1998) Activation of cerebellar climbing fibers increases cerebellar blood flow: role of glutamate receptors, nitric oxide, and cGMP. Stroke 29:499-507.

Yang X, Renken R, Hyder F, Siddeek M, Greer CA, Shepherd GM, Shulman RG (1998) Dynamic mapping at the laminar level of odor-elicited responses in rat olfactory bulb by functional MRI. Proc Natl Acad Sci USA 95:7715-7720.

Yuan Q, Harley CW, McLean JH, Knöpfel T (2002) Optical imaging of odor preference memory in the rat olfactory bulb. J Neurophysiol 87:3156-3159.

Zonta M, Angulo MC, Gobbo S, Rosengarten B, Hossmann KA, Pozzan T, Carmignoto G (2003) Neuron-to-astrocyte signaling is central to the dynamic control of brain microcirculation. Nat Neurosci 6:43-50. 